\title{
Consumer Adoption of Mobile Government in the Kingdom of Saudi Arabia: The Role of Usefulness, Ease of Use, Perceived Risk and Innovativeness
}

\author{
Abdullah Baabdullah ${ }^{1}$, Omar Nasseef ${ }^{1}$, and Ali Alalwan ${ }^{2}$ \\ ${ }^{1}$ Department of Management Information Systems, Faculty of Economics and Administration, \\ King Abdulaziz University, Jeddah, Kingdom of Saudi Arabia \\ \{baabdullah, onasseef\}@kau.edu.sa \\ ${ }^{2}$ Amman College of Banking and Finance, Al-Balqa' Applied University, Amman, Jordan \\ alwan.a.a.ali@gmail.com
}

\begin{abstract}
Utilising Mobile Government (M-Gov) services would raise socioeconomic benefits. Thus, it is essential to examine the factors that may increase the adoption of M-Gov services within the context of Saudi Arabia. This research aims to examine potential users' intentions towards different variables that may be significant for supporting higher behavioural intention to use the M-Gov services in Saudi Arabia. This study embraces the following variables: perceived risk, innovativeness, perceived usefulness, perceived ease of use and behavioural intention. Data was collected by means of a self-administered questionnaire on a convenience sample that consisted of 600 subjects with a response rate of $69.67 \%$. The findings were gathered and the statistical analysis suggested that the related variables are perceived as significant by participants and they have a strong behavioural intention to use the M-Gov services. Furthermore, the findings show that perceived ease of use significantly influences perceived usefulness.
\end{abstract}

Keywords: Saudi Arabia, M-Gov, TAM, perceived risk, innovativeness

\section{Introduction}

M-Gov deals with the group of services concerning the organised usage of the governmental services and utilisations that are mainly attainable via mobile phones [37]. The Saudi Government has aimed at increasing the adoption of M-Gov in order to offer citizens more accessibility to governmental services compared with traditional methods in terms of time and cost [7]. Nevertheless, the traditional channels for communicating and transacting with the government are still common in Saudi Arabia [3]. Saudi citizens have not adopted it quickly due to the risks associated with the adoption of M-Gov as well as the lack of Saudi infrastructure [2]. This study aims to explore the citizens' (potential users) perceptions on the significance of certain factors regarding the issue of M-Gov adoption in the domain of Saudi Arabia. 


\section{Literature Review}

Theoretically, within the field of IT/IS, researchers have integrated and formulated different theories and models in order to get in-depth knowledge and thoughtful understanding of the customers' behavioural intention towards M-Gov. Examples include the Theory of Reasoned Action (TRA) which was embraced by [8]. The Theory of Planned Behaviour (TPB) was applied by [32]. The Technology Acceptance Model (TAM) has also been implemented by [35], and it proposed to predict the customers' behavioural intention to use M-Gov. The Unified Theory of Acceptance and Use of Technology (UTAUT) [34] were implemented by [37]. The low level of M-Gov adoption in the context of Saudi Arabia was referred by [5]. [7] referred that the overt lack of consumers' awareness and the low levels of trust were considered as the main problems when it comes to the actual adoption of the M-Gov service on a larger scale. It is obvious that due to the newly established E-Gov services in Saudi Arabia, the issue of M-Gov has not, so far, been studied comprehensively. Consequently, this matter requires further research to investigate the shortage of M-Gov adoption.

\section{Conceptual model and research hypotheses}

TAM has been recognised as the most adopted theory within IT/IS research [34]. In order to solve the matter of inaccuracy in prediction with behavioural intention, the TAM has been extended by a number of researchers. For example, within the context of M-Gov, [3] extended the TAM model to include factors from the IDT model (relative advantage, compatibility, trialability). Likewise, [31] added elements from the IDT and UTAUT models to the TAM model. [8] developed their conceptual model relying on factors from TAM, TRA and UTAUT. As Figure 1 shows, this study adopts PU and PEOU from TAM and extended it to include perceived risk (PR) and innovativeness (INN).

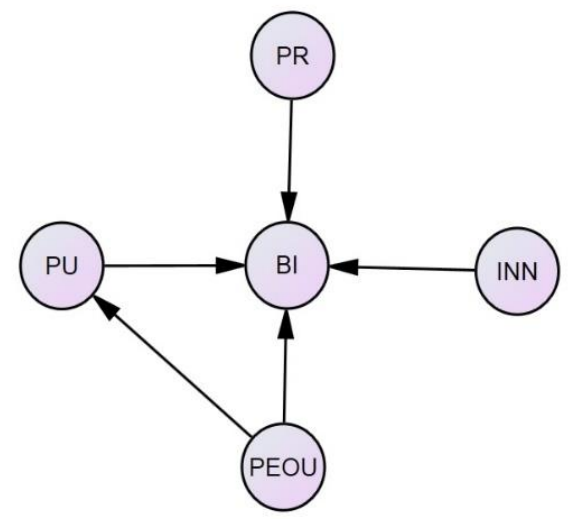

Figure 1. The Proposed Research Model - Adopted from [13] 
Perceived Usefulness $(P U)$ is defined as 'the degree to which a person believes that using a particular system would enhance his or her job performance' [14]. A considerable number of studies have affirmed the important role of PU over BI within the context of M-Gov (e.g. [22], [25]). Thus, the following hypothesis is: H1: PU positively influences Saudi customers' intention to use M-Gov. Perceived Ease of Use (PEOU) is described as 'the degree to which a person believes that using a particular system would be free of effort' [14]. Because of the unique trait of M-Gov which necessitates a specific amount of skill and knowledge, PEOU might have a significant role in influencing the customers' behavioural intention to adopt this service [30]. Furthermore, PEOU indirectly influences BI through facilitating the influence of PU on BI [38]. Accordingly, this paper concludes: H2: PEOU positively influences Saudi consumers' BI to adopt M-Gov. H3: PEOU positively influences PU of using M-Gov. [27] defines Perceived Risk (PR) as 'the consumer's subjective expectation of suffering a loss in pursuit of a desired outcome.' In M-Gov, the effect of PR on BI was significant [8], [31]. Similarly, it can be assumed that: H4: PR has a negative significant impact on consumers' BI to adopt M-Gov. [29] described Innovativeness (INN) as 'the level to which an individual is comparatively early in using novel thoughts than other members of a social system.' [3] referred that increased levels of innovativeness led to a higher positive influence on consumers' adoption of M-Gov services. The following hypothesis can be formulated for the MGov context: H5: Innovativeness has a significant and positive relationship with consumers' BI to adopt M-Gov.

\section{Methodology}

Since the researchers presupposed as having no list of Saudi M-Gov potential adopters and because the citizens are dispersed in different areas, this research employed convenience sampling (i.e. in Jeddah, Riyadh and Dammam). Twenty-two items of the selected constructs were derived from [1], [4], [13], [15], [23] and [39]. The level of responses was measured by the seven-point Likert scale.

\section{Results}

\subsection{Response Rate}

Table 1 outlines the distributed sample along with the returned responses, incomplete and problematic responses, and finally valid responses.

Table 1. Response Rate

\begin{tabular}{|l|c|c|}
\hline & M-Gov & $\%$ \\
\hline Sample & 600 & 100 \\
\hline Returned responses & 418 & 69.67 \\
\hline Incomplete and problematic responses & 22 & 3.67 \\
\hline Valid responses & 396 & 66 \\
\hline
\end{tabular}




\subsection{Data Screening}

Data screening was able to check whether the data was clean, reliable, useable and valid with a normal distribution before conducting further multivariate statistical analysis such as Structural Equation Modelling (SEM) [12].

\section{Treatment of Missing Data}

The amount of missing data and their distribution pattern has been examined in the data set based on [11] role, and the amount of missing data per construct was less than 0.05 and in an acceptable level. In addition, the $p$ value of missing completely at random (MCAR) was found to be non-significant in the data set $(p=0.483)$. This indicates that the missing data over the data set is in a random manner and its values also existed non-systematically. All the missing values have been filled by the variable mean value as recommended [33].

\section{Outliers}

Based on AMOS 22.0 outcomes, Mahalanobis-D squared distance $\left(\mathrm{D}^{2}\right)$ was used to screen multivariate outliers with a $p$ value of 0.000 over the data set as shown below in Table 2. In fact, the small amount of outliers is not problematic in the large sample size [24]. In addition to this, removing outliers may negatively reflect the generalisability of the results. Accordingly, it was decided to keep these outliers, as they could not improve the multivariate statistical results [18].

Table 2. Multivariate Outliers: Mahalanobis-D squared distance $\left(\mathrm{D}^{2}\right)$

\begin{tabular}{|c|c|c|c|}
\hline Observation number & Mahalanobis d-squared & $\mathrm{p} 1$ & $\mathrm{p} 2$ \\
\hline 61 & 86.862 & .000 & .000 \\
\hline 341 & 70.379 & .000 & .000 \\
\hline 20 & 70.017 & .000 & .000 \\
\hline 225 & 63.930 & .000 & .000 \\
\hline 29 & 63.617 & .000 & .000 \\
\hline 325 & 60.903 & .000 & .000 \\
\hline 158 & 60.758 & .000 & .000 \\
\hline 111 & 52.108 & .000 & .000 \\
\hline 233 & 50.717 & .000 & .000 \\
\hline
\end{tabular}

\section{Assessment of Normality}

Assessment of normality is meant to ensure that the attained data is normally distributed in a symmetrical shape. Accordingly, the univariate normality of each variable was examined by the skewness-kurtosis approach [10]. According to [36], the cut-off point of skewness and kurtosis values should be 3 and 8 respectively. As seen in Table 3 that represents AMOS 22.0 outcomes, the skewness-kurtosis approach was used over the data set, and all statistical values of this approach were found to be in an acceptable range. 
Table 3. Assessment of Normality

\begin{tabular}{|l|l|r|r|}
\hline \multicolumn{2}{|c|}{ Construct } & \multicolumn{2}{c|}{ M-Gov } \\
\hline Perceived Usefulness (PU) & Variable & Skewness & Kurtosis \\
\cline { 2 - 4 } & PU 1 & -1.320 & .754 \\
\cline { 2 - 4 } & PU 2 & -1.044 & .085 \\
\cline { 2 - 4 } & PU 3 & -1.025 & .034 \\
\cline { 2 - 4 } & PU 4 & -1.087 & .132 \\
\hline Perceived Ease of Use (PEOU) & PEOU 1 & -.729 & -.271 \\
\cline { 2 - 4 } & PEOU 2 & -.687 & -.370 \\
\cline { 2 - 4 } & PEOU 3 & -.733 & -.401 \\
\cline { 2 - 4 } & PEOU 4 & -.969 & .312 \\
\hline Innovativeness (INN) & INN1 & -1.133 & 1.138 \\
\cline { 2 - 4 } & INN2 & -1.287 & 1.680 \\
\cline { 2 - 4 } & INN3 & -.448 & -.604 \\
\cline { 2 - 4 } & INN4 & -1.038 & .584 \\
\cline { 2 - 4 } & INN5 & -.861 & -.590 \\
\cline { 2 - 4 } & INN6 & -.671 & -.686 \\
\hline Perceived Risk (PR) & PR1 & .077 & 1.221 \\
\cline { 2 - 4 } & PR2 & .635 & 2.939 \\
\cline { 2 - 4 } & PR3 & .274 & .486 \\
\cline { 2 - 4 } & PR4 & .072 & .378 \\
\cline { 2 - 4 } & PR5 & -.037 & -.388 \\
\hline Behavioural Intention (BI) & BI1 & -1.415 & 1.043 \\
\cline { 2 - 4 } & BI2 & -1.531 & 1.420 \\
\cline { 2 - 4 } & BI3 & -1.327 & .787 \\
\hline
\end{tabular}

\section{Respondents' Profile and Characteristics}

Table 4 below shows the demographic characteristics of respondents (i.e. Gender, Age, Education, Occupation, and Monthly Income).

Table 4. Demographic Characteristics of Respondents

\begin{tabular}{|c|c|c|}
\hline Demographic Profile & Number of Respondents $(\mathrm{N}=307)$ & Percentage $(\%)$ \\
\hline \multicolumn{3}{|l|}{ Gender } \\
\hline Male & 228 & 57.6 \\
\hline Female & 168 & 42.4 \\
\hline Total & 396 & 100 \\
\hline \multicolumn{3}{|l|}{ Age } \\
\hline$>=18-20$ & 25 & 6.3 \\
\hline $21-29$ & 40 & 10.1 \\
\hline $30-39$ & 230 & 58.1 \\
\hline $40-49$ & 64 & 16.2 \\
\hline 50 and above & 37 & 9.3 \\
\hline Total & 396 & 100 \\
\hline \multicolumn{3}{|l|}{ Education } \\
\hline Less than High School & 7 & 1.8 \\
\hline
\end{tabular}




\begin{tabular}{|l|c|c|}
\hline High School & 57 & 14.4 \\
\hline Diploma & 82 & 20.7 \\
\hline Bachelor & 170 & 42.9 \\
\hline Postgraduate & 80 & 20.2 \\
\hline Total & 396 & 100 \\
\hline Occupation & 35 & 8.8 \\
\hline Student & 253 & 63.9 \\
\hline Government employee & 63 & 15.9 \\
\hline Private sector employee & 45 & 11.4 \\
\hline Self employed & 396 & 100 \\
\hline Total & 30 & 7.6 \\
\hline Monthly income (Saudi Riyals) & 16.2 \\
\hline $1000-4000$ & 64 & 53.5 \\
\hline $4001-8000$ & 212 & 11.1 \\
\hline $8001-14000$ & 44 & 11.6 \\
\hline $14001-20000$ & 46 & 100 \\
\hline More than 20000 & 396 & \\
\hline Total & \multicolumn{2}{|c|}{} \\
\hline
\end{tabular}

\section{Structural Equation Modelling (SEM)}

SEM is an approach that is made from two stages. The first stage is the reliability and validity of the constructs and then the fitness of the model are examined via CFA [10]. The second stage (i.e. structural model) examined the path coefficients between the endogenous variables (i.e. PU, PEOU, PR and INN) and the exogenous construct (i.e. BI) were checked. The relationship was also tested between PEOU and PU.

\subsection{Measurement Model: Confirmatory Factor Analysis (CFA)}

\section{Model Fitness}

For the purpose of testing the level of unidimensionality and the model's goodness of fit, a number of fit indices were used as seen below in Table 5 [21]. All the latent constructs were measured and their own indicators ( 22 items). The model is fitting the data according to the fit indices. According to [9], there is a need for a few respecifications and refinements. This process is meant to improve the model fitness by looking at standardised regression weights, modification indices and standardised covariance matrix. It was observed that PR1, 3 and INN1, 5 and 6 had an unacceptable higher value based on the modification indices, and thus all of them were removed. It was also found that the standardised residual values were within the acceptable range of \pm 2.58 as recommended by [17]. Finally, and as suggested by [10], the CFA was tested once more to ensure the goodness of fit of the modified measurement model to see if it was sufficiently enhanced. Accordingly, no extra modifications were conducted regarding the measurement model. 
Table 5. Measurement Model

\begin{tabular}{|l|c|c|c|}
\hline Fit Indices & Cut-off Point & Measurement Model & Modified Measurement Model \\
\hline CMIN/DF & $\leq 3.00$ & 1.900 & 1.488 \\
\hline GFI & $\geq .90$ & .922 & .955 \\
\hline AGFI & $\geq .80$ & .901 & .937 \\
\hline NFI & $\geq .90$ & .935 & .965 \\
\hline CFI & $\geq .90$ & .968 & .988 \\
\hline RMSEA & $\leq 0.08$ & .048 & .035 \\
\hline
\end{tabular}

\section{Construct Reliability}

Internal consistency (Cronbach's alpha), CR and AVE were employed to check the reliability of each construct after unidimenstionality of the goodness of fit of the measurement model was tested [9]. Accordingly, and as Table 6 shows, adequate values of internal consistency, CR and AVE were realised.

Table 6. Constructs' Reliability

\begin{tabular}{|l|c|c|c|}
\hline Latent Constructs & Cronbach's alpha $(\alpha)$ & Composite Reliability (CR) & Average Variance Extracted (AVE) \\
\hline PU & .910 & .909 & .715 \\
\hline PEOU & .874 & .875 & .637 \\
\hline PR & .780 & .775 & .535 \\
\hline INN & .758 & .843 & .649 \\
\hline BI & .947 & .947 & .860 \\
\hline
\end{tabular}

\section{Construct Validity}

The CFA was used to examine the constructs' validity of the conceptual model; both convergent and discriminant. [19] indicated that all items should have standardised regression weights above the cut-off value of .50 . As seen in Table 7 , all values were above .50. A threshold that is less than .85 has to be attained for all of the intercorrelation measurement [19]. According to the correlations table, the measurements of all of the inter-correlations attained this condition. As it can be seen in Table 8, the inter-correlation values with other similar constructs were no more than the square root of AVE given for each latent constructs [16]. Therefore, the conceptual model's estimations achieved a reliable level when it comes to the validity of convergent and discriminant.

Table 7. Constructs' Validity

\begin{tabular}{|l|l|c|}
\hline Latent Constructs & \multicolumn{1}{|c|}{ Items } & Factor Loading \\
\hline \multirow{4}{*}{ PU } & PU1 & .915 \\
\cline { 2 - 3 } & PU2 & .818 \\
\cline { 2 - 3 } & PU3 & .810 \\
\cline { 2 - 3 } & PU4 & .835 \\
\hline PEOU & PEOU1 & .803 \\
\cline { 2 - 3 } & PEOU2 & .759 \\
\cline { 2 - 3 } & PEOU3 & .814 \\
\cline { 2 - 3 } & PEOU4 & .813 \\
\hline PR & PR2 & .661 \\
\hline
\end{tabular}




\begin{tabular}{|l|l|l|}
\hline \multirow{4}{*}{ INN } & PR4 & .774 \\
\cline { 2 - 3 } & PR5 & .755 \\
\hline \multirow{4}{*}{ BI } & INN2 & .860 \\
\cline { 2 - 3 } & INN3 & .599 \\
\cline { 2 - 3 } & INN4 & .921 \\
\hline & BI1 & .931 \\
\cline { 2 - 3 } & BI2 & .945 \\
\cline { 2 - 3 } & BI3 & .901 \\
\hline
\end{tabular}

Table 8. Discriminant Validity

\begin{tabular}{|c|c|c|c|c|c|}
\hline Latent Constructs & PU & PEOU & PR & INN & BI \\
\hline PU & $\mathbf{. 8 4 6}$ & & & & \\
\hline PEOU & .710 & $\mathbf{. 7 9 8}$ & & & \\
\hline PR & -.317 & -.363 &. $\mathbf{7 3 2}$ & & \\
\hline INN & .563 & .515 & -.449 & $\mathbf{. 8 0 5}$ & \\
\hline BI & .618 & .578 & -.447 & .578 & $\mathbf{. 9 2 7}$ \\
\hline
\end{tabular}

\section{Common Method Bias}

This study considered Harman's single factor in order to check the common method bias (CMB) in the data set, and the 17 scale items [20]. All items in Table 9 were inspected by using an unrotated factor solution after loading the items into the EFA. According to [28], the first factor was able to account for less than the cut-off value of $50 \%$ as shown in the statistical results $(44.864 \%$ of variance); otherwise, no factor was able to develop. Thus, the data set is perceived to be reliable, and there are no concerns about the CMB.

Table 9. Common Method Bias Test Total Variance Explained

\begin{tabular}{|c|c|c|c|c|c|c|}
\hline \multicolumn{7}{|c|}{ Initial Eigenvalues } \\
\hline \multirow{2}{*}{ Component } & \multicolumn{7}{|c|}{ \% } & \multicolumn{2}{c|}{ Extraction Sums of Squared Loadings } \\
\hline & Total & \% of Variance & Cumulative \% & Total & \% of Variance & Cumulative \% \\
\hline 1 & 7.627 & 44.864 & 44.864 & 7.627 & 44.864 & 44.864 \\
\hline 2 & 1.802 & 10.600 & 55.464 & & & \\
\hline 3 & 1.298 & 7.637 & 63.101 & & & \\
\hline 4 & 1.200 & 7.058 & 70.158 & & & \\
\hline 5 & 1.096 & 6.446 & 76.604 & & & \\
\hline 6 & .649 & 3.816 & 80.420 & & & \\
\hline 7 & .538 & 3.163 & 83.583 & & & \\
\hline 8 & .466 & 2.740 & 86.323 & & & \\
\hline 9 & .441 & 2.594 & 88.917 & & & \\
\hline 10 & .359 & 2.111 & 91.028 & & & \\
\hline 11 & .314 & 1.849 & 92.877 & & & \\
\hline 12 & .308 & 1.810 & 94.687 & & & \\
\hline 13 & .240 & 1.412 & 96.099 & & & \\
\hline 14 & .211 & 1.242 & 97.340 & & & \\
\hline 15 & .180 & 1.060 & 98.400 & & & \\
\hline 16 & .164 & .962 & 99.363 & & & \\
\hline 17 & .108 & .637 & 100.000 & & & \\
\hline \multicolumn{7}{|c|}{ Extraction Method: Principal Component Analysis. } \\
\hline
\end{tabular}




\section{Structural Model}

The conceptual model was validated and the causal paths between the dependent and independent factors were tested - See Figure 2. The structural model was examined at the second stage of the SEM. The structural model adequately fits the data based on the fit indices (see Table 10). A variance of .50 in BI and of .53 in PU was explained. The standardised estimates of the structural model are detailed below in Table 11.

Table 10. Structural Model

\begin{tabular}{|c|c|c|}
\hline Fit Indices & Cut-off Point & Structural Model \\
\hline CMIN/DF & $\leq 3.00$ & 1.714 \\
\hline GFI & $\geq .90$ & .948 \\
\hline AGFI & $\geq .80$ & .928 \\
\hline NFI & $\geq .90$ & .958 \\
\hline CFI & $\geq .90$ & .982 \\
\hline RMSEA & $\leq 0.08$ & .043 \\
\hline
\end{tabular}

Table 11. Standardised Estimates of the Structural Model

\begin{tabular}{|c|c|c|c|c|}
\hline Path & Standardised Estimate & Critical Ratio & P-value & Significance \\
\hline $\mathrm{PU} \rightarrow \mathrm{BI}$ & .308 & 4.500 & $* * *$ & Significant \\
\hline $\mathrm{PEOU} \rightarrow \mathrm{BI}$ & .173 & 2.418 & .016 & Significant \\
\hline $\mathrm{PR} \rightarrow \mathrm{BI}$ & -.184 & -3.306 & $* * *$ & Significant \\
\hline $\mathrm{INN} \rightarrow \mathrm{BI}$ & .243 & 4.334 & $* * *$ & Significant \\
\hline $\mathrm{PEOU} \rightarrow \mathrm{PU}$ & .729 & 13.090 & $* * *$ & Significant \\
\hline
\end{tabular}

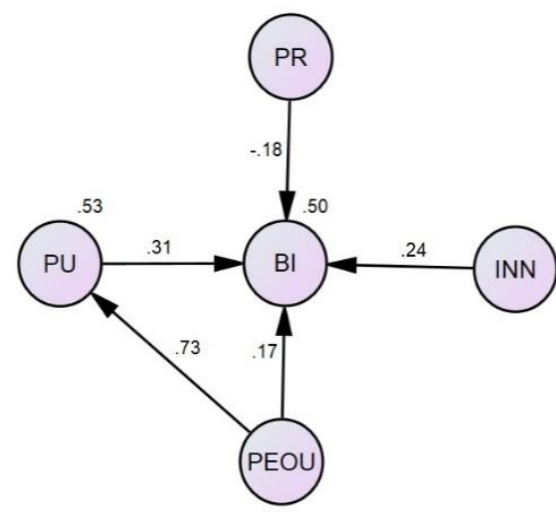

Figure 2. Validation of the Conceptual Model

\section{Discussion}

The statistical findings affirmed the predictive power of the adopted conceptual model in interpreting suitable variances explained on the dependent factors (i.e. PU and BI) see Figure 2. In detail, the statistical findings strongly affirmed that PU is a main factor anticipating of BI with $(\gamma=.31)$. This means that Saudi customers tend to have a stronger behavioural intention to use M-Gov when considering this technology as 
productive, useful and effective during their routine life. The empirical outcomes asserted that PEOU has significant influence over BI with $17 \%$. As such, the Saudi customers will have a higher behavioural intention to use M-Gov when they perceive the service is easy and only takes a few efforts to use. Indeed, it can be seen that although PEOU has significant influence over BI; yet, it has the least effect amongst other independent variables over BI. This is because the fact that conducting M-Gov requires customers to have some knowledge of using the system which might be difficult in some cases. Interestingly, PEOU significantly influences the PU with $(\gamma=.73)$. This indicates that customers will perceive M-Gov as a useful service when considering that this service is easy to handle. Accordingly, it is considerably importance to assert the role of INN when pursuing to increase the customers' behavioural intention to use M-Gov. This study shows the significance of this path $(\gamma=.24)$. This can be explained by the idea that economic prosperity in the Kingdom of Saudi Arabia allows the consumers to experience new technologies and novel products or services such as M-Gov. This study measured the negative importance effect of PR over BI in M-Gov $(\gamma=-.18)$. Thus, this paper suggests that PR is recognised by Saudi customers as a significant aspect in shaping their behavioural intention to accept or discard the M-Gov in terms of social, financial, performance, and psychological risks.

\subsection{Contribution}

The achievement of this research is estimated to add to the context of M-Gov and to Saudi Arabia's initiatives in developing M-Gov applications as well as citizens' behavioural intention towards using this new promised service. Furthermore, this study theoretically adds to the literature by extending TAM to include two powerful factors to enhance the citizens' intention to shape an actual behaviour.

\section{Conclusion}

This study measured the influence of PU, PEOU, INN and PR on BI to use M-Gov within the Saudi Arabian context. The findings indicated that the aforementioned independent factors positively influenced BI; also, PEOU significantly influences PU.

\subsection{Limitations and Future Research Directions}

This study only examines M-Gov which, in turn, adversely reflects on the outcomes' generalisability to other types of mobile services. Future research should consider other contexts and technologies such as the Mobile Internet. As this study considers investigating behavioural intention instead of actual use of M-Gov in Saudi Arabia, future research should provide a complete view about the actual usage in addition to new effective factors to provide a more comprehensive model.

\section{References}


1. Agarwal, R., Prasad, J.: A conceptual and operational definition of personal innovativeness in the domain of information technology. Information Systems Research, 9(2), 204-215 (1998).

2. Ahmad, T., Ansari, A. A., Akhtar, A., Parveen, S.: Current review of ICT and mgovernment services in Saudi Arabia. International Journal of Computer Engineering and Applications, 7(2) (2014).

3. Al-Busaidi, H. A. S.: A model of intention to use m-gov services. (Doctoral dissertation, Victoria University) (2012).

4. Aldás-Manzano, J., Ruiz-Mafé, C., Sanz-Blas, S.: Exploring individual personality factors as drivers of m-shopping acceptance. Industrial Management and Data Systems, 109(6), 739-757 (2009).

5. Al-Khalifa, H. S.: Development of m-gov websites: A functional design approach. In Proceedings of the 13th International Conference on Information Integration and Web-based Applications and Services (pp.455-458). ACM (2011).

6. Aloudat, A., Michael, K., Chen, X., Al-Debei, M. M.: Social acceptance of locationbased m-gov services for emergency management. Telematics and Informatics, 31(1), 153-171 (2014).

7. Alsenaidy, A., Ahmad, T.: A review of current state m-gov in Saudi Arabia. Department of Biochemistry, King Saud University (2012).

8. Althunibat, A., Zain, N. A. M., Ashaari, N. S.: Modelling the factors that influence m-gov services acceptance. African Journal of Business Management, 5(34), 1303013043 (2011).

9. Anderson, J. C. Gerbing, D. W.: Structural equation modelling in practice: A review and recommended two-step approach. Psychological Bulletin, 103(3), 411-423 (1988).

10. Byrne, B. M.: Structural equation modeling with AMOS: Basic concepts, applications and programming. $6^{\text {th }}$ edn. New York, USA: Taylor and Francis Group (2010).

11. Churchill, G. A.: Marketing research methodological foundation. $6^{\text {th }}$ edn. Orlando, Florida: The Dryden Press (1995).

12. Coakes, S. J.: SPSS: Analysis without anguish: Version 14.0 for Windows. Milton, Qld: John Wiley and Sons (2006).

13. Davis, F. D.: Perceived usefulness, perceived ease of use, and user acceptance of information technology. MIS Quarterly, 319-340 (1989).

14. Davis, F. D., Bagozzi, R. P. Warshaw, P. R.: User acceptance of computer technology: a comparison of two theoretical models. Management Science, 35(8), pp. 982-1003 (1989).

15. Featherman, M. S., Pavlou, P. A.: Predicting e-services adoption: A perceived risk facets perspective. International Journal of Human-Computer Studies, 59(4), 451-474 (2003).

16. Fornell, C., Larcker, D. F.: Evaluating structural equation models with unobservable variables and measurement error. Journal of Marketing Research, 18(1), 39-50 (1981)

17. Hair Jr., J. F., Anderson, R. E., Tatham, R. L. Black, W. C.: Multivariate data analysis with readings. Englewood Cliffs, NJ: Prentice-Hall (1995).

18. Hair Jr., J. F., Black, W., Babin, B., Anderson, R. E., Tatham, R.: Multivariate data analysis. $6^{\text {th }}$ edn. New Jersey: Prentice Hall (2006).

19. Hair Jr., J. F., Black, W. C., Babin, B. J., Anderson, R. E.: Multivariate data analysis: A global perspective. $7^{\text {th }}$ edn. Pearson Education International (2010).

20. Harman, H. H.: Modern factor analysis. $3^{\text {rd }}$ edn. Chicago, IL: University of Chicago Press (1976). 
21. Hooper, D., Coughlan, J., Mullen, M. R.: Structural equation modelling: Guidelines for determining model fit. Electronic Journal of Business Research Methods, 6(1), 53-60 (2008).

22. Hung, S. Y., Chang, C. M., Kuo, S. R.: User acceptance of mobile e-government services: An empirical study. Government Information Quarterly, 30(1), 33-44 (2013).

23. Karaiskos, D. C., Kourouthanassis, P., Lantzouni, P., Giaglis, G. M., Georgiadis, C. $\mathrm{K}$.: Understanding the adoption of mobile data services: Differences among mobile portal and mobile internet users. In Mobile Business, 2009. ICMB 2009. $8^{\text {th }}$ International Conference on (pp.12-17). IEEE (2009).

24. Kline, R. B.: Principles and practice of structural equation modelling. New York: The Guilford Press (1998).

25. Lu, J., Liu, C., Yu, C. S., Wang, K.: Determinants of accepting wireless mobile data services in China. Information \& Management, 45(1), 52-64 (2008).

26. Nunnally, J. C.: Psychometric theory. New York, NY: McGraw-Hill (1978).

27. Pavlou, P. A.: Integrating trust in electronic commerce with the technology acceptance model: Model development and validation. In J. De Gross (ed.), Proceedings of the Seventh Americas Conference in Information Systems, (pp. 816822). New York: ACM (2001).

28. Podsakoff, P. M., MacKenzie, S. B., Lee, J. Y., Podsakoff, N. P.: Common method biases in behavioral research: A critical review of the literature and recommended remedies. Journal of Applied Psychology, 88(5), 879 (2003).

29. Rogers, E. M., Medina, U. E., Rivera, M. A., Wiley, C. J.: Complex adaptive systems and the diffusion of innovations. The Innovation Journal: The Public Sector Innovation Journal, 10(3), 1-26 (2005).

30. Shareef, M. A., Archer, N., Dwivedi, Y. K.: Examining adoption behavior of mobile government. Journal of Computer Information Systems, 53(2), 39-49 (2012).

31. Susanto, T. D., Goodwin, R.: Factors influencing citizen adoption of SMS-based egovernment services. Electronic Journal of e-Government, 8(1), 55-71 (2010).

32. Susanto, T. D., Goodwin, R.: User acceptance of SMS-based e-government services: Differences between adopters and non-adopters. Government Information Quarterly (2013).

33. Tabachnick, B. G., Fidell, L. S.: Using multivariate statistics. Boston: Pearson Education (2007).

34. Venkatesh, V., Morris, M. G., Davis, G. B., Davis, F. D.: User acceptance of information technology: Toward a unified view. MIS Quarterly, 425-478 (2003).

35. Wang, C.: Antecedents and consequences of perceived value in mobile government continuance use: An empirical research in China. Computers in Human Behavior, 34, 140-147 (2014).

36. West, S. G., Finch, J. F., Curran, P. J.: Structural equation models with non-normal variables: Problems and remedies. In R. H. Hoyle (ed.), Structural equation modelling: Concepts, issues, and applications (pp.56-75). Thousand Oaks, CA: Sage (1995).

37. Yfantis, V., Vassilopoulou, K., Pateli, A., Usoro, A.: The influential factors of mgov's adoption in the developing countries. In Mobile Web and Information Systems (pp.157-171). Berlin Heidelberg: Springer (2013).

38. Zarmpou, T., Saprikis, V., Markos, A., Vlachopoulou, M.: Modeling users' acceptance of mobile services. Electronic Commerce Research, 12(2), 225-248 (2012).

39. Zhou, T.: Understanding users' initial trust in mobile banking: An elaboration likelihood perspective. Computers in Human Behavior, 28(4), 1518-1525 (2012). 